\title{
Conductivity behaviour of polymer gel electrolytes: Role of polymer
}

\author{
S S SEKHON \\ Department of Applied Physics, Guru Nanak Dev University, Amritsar 143 005, India
}

MS received 1 March 2003

\begin{abstract}
Polymer is an important constituent of polymer gel electrolytes along with salt and solvent. The salt provides ions for conduction and the solvent helps in the dissolution of the salt and also provides the medium for ion conduction. Although the polymer added provides mechanical stability to the electrolytes yet its effect on the conductivity behaviour of gel electrolytes as well as the interaction of polymer with salt and solvent has not been conclusively established. The conductivity of lithium ion conducting polymer gel electrolytes decreases with the addition of polymer whereas in the case of proton conducting polymer gel electrolytes an increase in conductivity has been observed with polymer addition. This has been explained to be due to the role of polymer in increasing viscosity and carrier concentration in these gel electrolytes.
\end{abstract}

Keywords. Polymer gel electrolytes; carboxylic acids; conductivity; ion dissociation.

\section{Introduction}

Gels are generally defined as 'polymers and their swollen matters with three dimensional network structures that are insoluble in any solvents' and gels exist under special conditions not found in solids, liquids and gases (Osada and Kajiwara 2001). The swollen gels that have absorbed a large amount of solvent are in the states between solids and liquids and their properties vary from viscous liquids to hard solids according to the chemical composition and other factors.

Polymer gels consist of a polymer network and solvents in which the polymer network envelopes the liquid and prevents it from escaping or in other words plays the role of a container that can hold a large amount of solvent and as a result possesses the characteristics of both liquids and solids. The properties of polymer gels have been found to depend upon the structure of the polymer network that makes up the gel as well as on the interaction of the network and the solvent. As the polymer networks are solvated by a large amount of the trapped solvent so gels generally possess high mobility.

The replacement of the solvent by liquid electrolyte having high value of conductivity results in polymer gel electrolytes. They are generally salt-solvent-polymer hybrid systems in which first a salt solution is prepared and then it is immobilized with the help of a suitable polymer matrix. Since the first report of high conductivity in lithium ion conducting polymer gel electrolytes (Feuillade and Perche 1975), these materials are receiving much attention due to some of their unique properties like high value of conductivity at room temperature $\left(10^{-2}-10^{-4} \mathrm{~S} / \mathrm{cm}\right)$, ease of preparation, wide range of composition and hence wider control of properties, good adhesive properties suitable for lamination, good thermal/electrochemical stability etc. The interest in these materials is due to their potential applications in solid state batteries, electrochromic devices, fuel cells, supercapacitors etc (Abraham and Alamgir 1994).

Most of the work reported is on lithium ion conducting polymer gel electrolytes which is due to their use as electrolytes in high energy density lithium batteries (Scrosati 2000). In addition to that recently some work on proton conducting polymer gel electrolytes have also been reported due to their suitability as a proton conducting membrane in polymer electrolyte membrane fuel cells (PEMFC) and other devices (Colomban 1992).

In polymer gel electrolytes the salt generally provides free/mobile ions which take part in the conduction process and the solvent helps in solvating the salt and also acts as a conducting medium whereas the polymer is reported to provide mechanical stability by increasing the viscosity of electrolyte (Sekhon et al 1998). The possible interactions between the polymer and salt/solvent have not been clearly understood. The salt used should generally have large anions and low dissociation energy so that it easily dissociates whereas the solvent used should have high dielectric constant, low viscosity and high boiling point and low melting point. The addition of polymer to lithium ion conducting polymer gel electrolytes has been generally found (Bohnke et al 1993) to result in an increase in viscosity due to which mobility decreases and as a result conductivity also decreases $(\sigma=$ $n q \mu$ ), whereas in the case of proton conducting polymer gel electrolytes containing weak acids the addition of polymer has been reported (Chandra et al 2000; Ericson et al 2000; Sekhon and Singh 2002; Sekhon et al 2002; Singh and Sekhon 2002) to result in an increase in conductivity. 
In view of different effect of the polymer in lithium and proton conducting polymer gel electrolytes, detailed studies are required to understand the role of polymer on the conductivity behaviour of polymer gel electrolytes. In the present paper the role of different polymers viz. poly (methylmethacrylate) (PMMA), poly(acrylonitrile) (PAN), poly(ethylene oxide) (PEO), poly(vinylidene fluoride) (PVdF), poly(vinylidene fluoride-co-hexafluoropropylene) (PVdF-HFP) on the conductivity behaviour of polymer gel electrolytes containing various lithium salts and various carboxylic acids has been discussed. The variation of conductivity with polymer addition has been explained on the basis of changes in carrier concentration and viscosity. Different results obtained in lithium and protonconducting gels have been discussed on the basis of the dissociation constant values.

\section{Experimental}

Liquid electrolytes are prepared by dissolving stoichiometric quantities of the salt/acid in a suitable solvent and concentration is generally expressed as molarity value (mol/l). Gel electrolytes are prepared by adding polymer in different concentrations (expressed as wt.\% of liquid electrolyte) to the liquid electrolyte. The mixture is continuously stirred along with moderate heating so that uniform gel is formed. The conductivity of liquid electrolytes is measured by using WTW LF330 conductivity meter, which is regularly calibrated by using standard $\mathrm{KCl}$ solution whereas the conductivity of gel electrolytes is measured by a.c. impedance spectroscopy using HP4284A precision LCR meter in the $20 \mathrm{~Hz}-1 \mathrm{MHz}$ frequency range. The details of the conductivity measurements have been described elsewhere (Sekhon et al 1998, 2002).

\section{Results and discussion}

Lithium ion conducting polymer gel electrolytes were prepared by adding polymer (PMMA, PAN, PEO) to the $1 \mathrm{M}$ solution of different lithium salts $\left(\mathrm{LiClO}_{4}, \mathrm{LiCF}_{3} \mathrm{SO}_{3}\right.$, $\left.\mathrm{LiN}\left(\mathrm{CF}_{3} \mathrm{SO}_{2}\right)_{2}\right)$ in solvents based upon ethylene carbonate (EC), propylene carbonate (PC), dimethylformamide (DMF) and dimethyl sulphoxide (DMSO). The conductivity of these gel electrolytes was measured as a function of polymer concentration (expressed as wt.\% of liquid electrolytes) and is given in figures 1,2 and 3 for PMMA-, PAN- and PEO-based gel electrolytes. It has been observed that the conductivity of liquid electrolytes containing different lithium salts is in the range of $10^{-3} \mathrm{~S} /$ $\mathrm{cm}$. The conductivity decreases with an increase in polymer content but the decrease in conductivity is small and is by a factor only and not by an order and the conductivity of gel electrolytes with high polymer content is also in the $10^{-3} \mathrm{~S} / \mathrm{cm}$ range. The addition of polymer generally results in an increase in viscosity $(\eta)$, which results in a decrease in mobility $(\mu)$ and as a result conductivity decreases. The measurement of viscosity as a function of polymer concentration shows an increase with polymer addition (Bohnke et al 1993). However, a distinction shall be made between microscopic and macroscopic viscosities. The experimentally measured viscosity is the macroscopic viscosity of the gel whereas the relation between carrier mobility $(\mu)$ and viscosity $(\eta)$ i.e. $\mu=q / 6 \pi r \eta$,

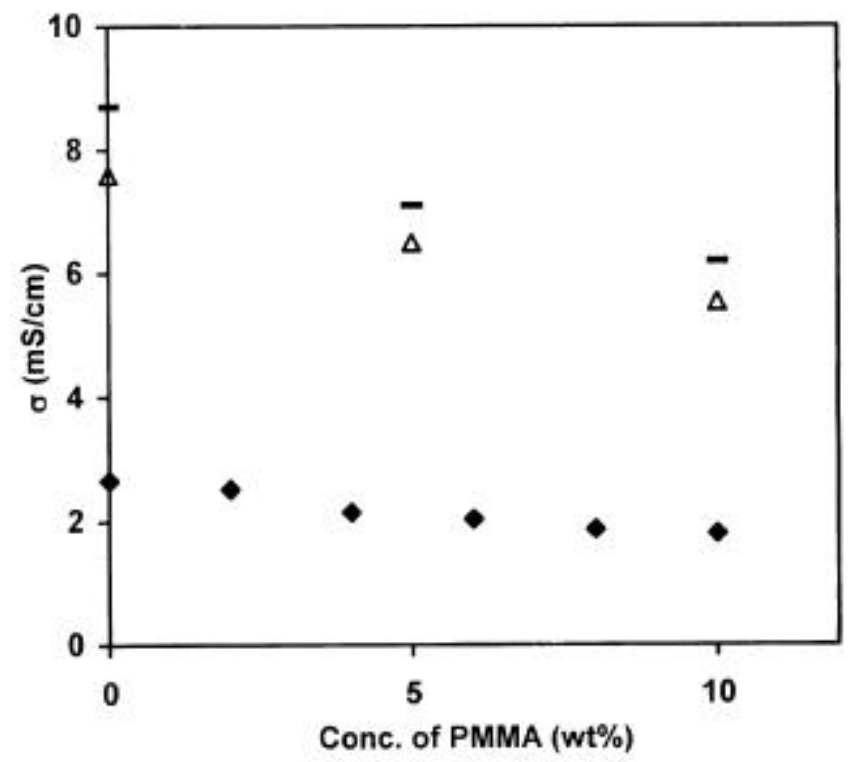

Figure 1. Variation of conductivity with PMMA concentration for gel electrolytes containing $1 \mathrm{M} \mathrm{LiClO}_{4}(\Delta), \mathrm{LiCF}_{3} \mathrm{SO}_{3}$ $(\diamond)$ and $\mathrm{LiN}\left(\mathrm{CF}_{3} \mathrm{SO}_{2}\right)_{2}(-)$ in $\mathrm{EC}: \mathrm{PC}$.

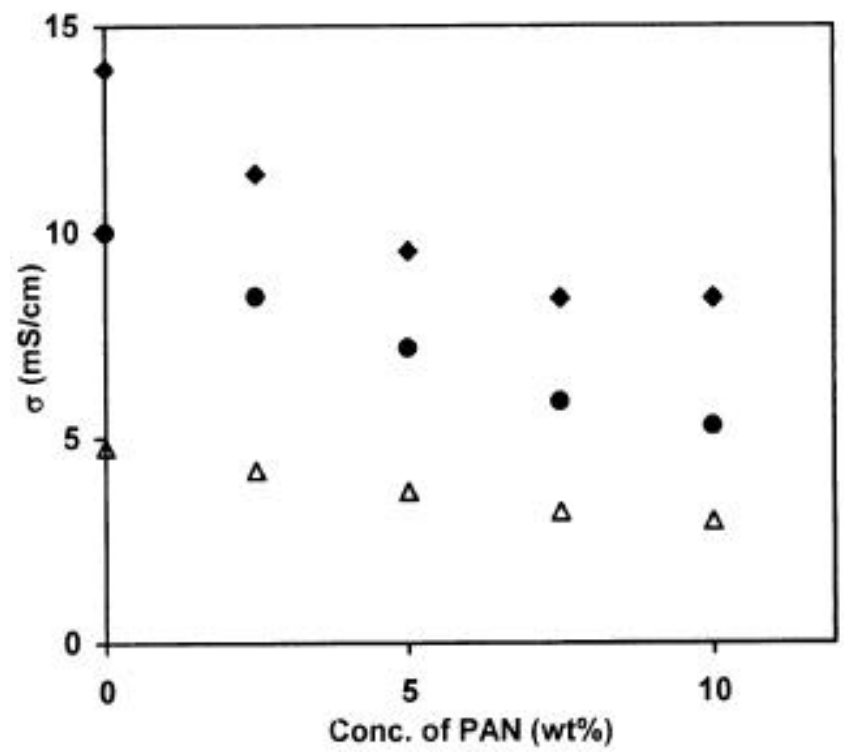

Figure 2. Variation of conductivity with PAN concentration for gel electrolytes containing liquid electrolytes of $1 \mathrm{M}$ $\mathrm{LiCF}_{3} \mathrm{SO}_{3}(\Delta)$ in $\mathrm{EC}$ and $1 \mathrm{M} \mathrm{LiClO}_{4}$ in DMSO $(\bullet)$ and $\mathrm{EC}$ : PC : DMF $(\diamond)$. 
where $q$ and $r$ are the charge and radius of the mobile ion, involves microscopic viscosity. If a continuous path is available through the solvent for the ions to move in then the overall macroscopic viscosity is not related to the ion mobility. The small decrease in conductivity observed with polymer addition suggests that the polymer does not take part in the conduction process but simply acts as a stiffener only. Similar results have also been reported with other lithium salts and polymers (Weber 1991; Koksbang et al 1994; Agnihotry et al 2000; Arora and Sekhon 2000; Sekhon 2000).

The polymer-salt, solvent interactions in lithium ion conducting polymer gel electrolytes have also been studied by using FTIR (Wang et al 1999), Raman (Cazzanelli et al 1995; Ostrovskii et al 1998), NMR/PFG NMR (Saito et al 2000), ESR (Qureshi et al 1998) and photon correlation spectroscopy (Svanberg et al 2000) techniques. In the widely studied PMMA-PC- $\mathrm{LiClO}_{4}$ gel electrolytes, the polymer matrix has been reported to play a passive role at low (0-35 wt.\%) PMMA concentrations and gel electrolytes has been considered as a liquid electrolyte encaged in a polymer matrix (Bohnke et al 1993). However, ESR studies on this gel system shows that the direct interactions of cations $\left(\mathrm{Li}^{+}\right)$with PMMA are largely responsible for increase in viscosity with salt addition. Similarly in PMMA/PAN-EC/PC- $\mathrm{LiClO}_{4}$ gel electrolytes the influence of polymer on ion-solvent interactions has been found to depend upon the nature of the polymer used. PMMA based gel electrolytes do not show any strong interaction between various components whereas PAN based gel electrolytes show strong electrolyte-polymer interactions, which may be due to the presence of polar $\mathrm{C} \equiv \mathrm{N}$ group in the monomer of PAN $\left(-\mathrm{CH}_{2} \mathrm{CHC} \equiv \mathrm{N}-\right)$. The addition of PAN to $\mathrm{PC}-\mathrm{LiClO}_{4}$ has

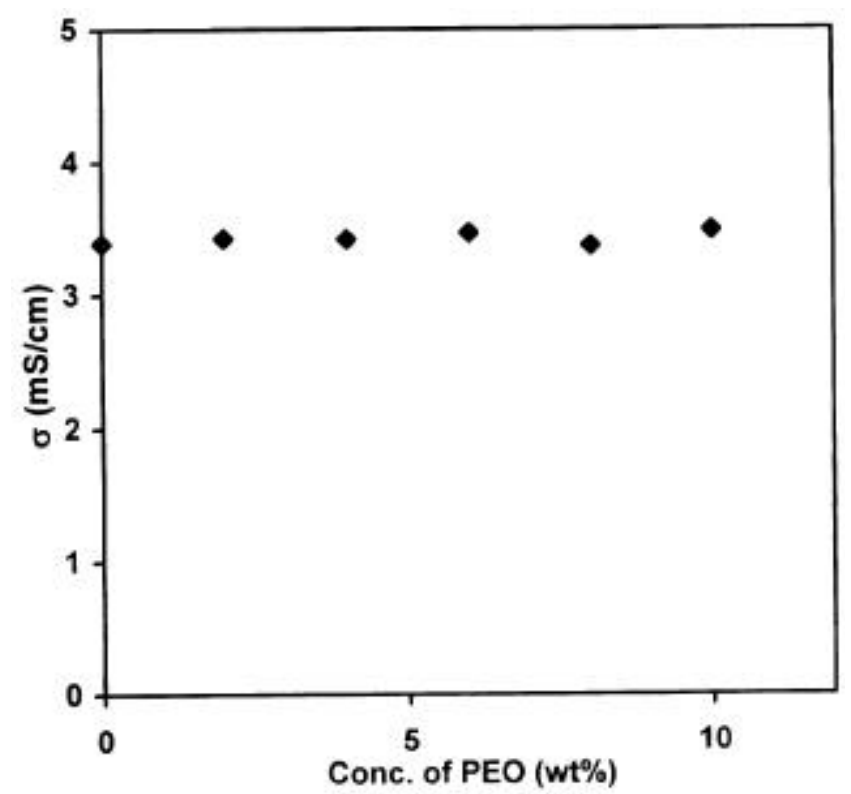

Figure 3. Variation of conductivity with $\mathrm{PEO}$ concentration for gel electrolytes containing $1 \mathrm{M} \mathrm{LiCF}_{3} \mathrm{SO}_{3}$ in EC : PC. been reported to suppress $\mathrm{Li}^{+}-\mathrm{PC}$ interaction and $\mathrm{Li}^{+}-$ PAN interaction is observed which depends upon the content of PAN in gel electrolytes.

Similarly detailed investigation on $\mathrm{LiN}\left(\mathrm{CF}_{3} \mathrm{SO}_{2}\right)_{2}-\mathrm{EC} /$ DEC-PVdF, PVdF-HFP gel electrolytes by pulsed field gradient NMR shows that the diffusion coefficient of cation $\left(\mathrm{Li}^{+}\right)$and anion $\left(\mathrm{F}^{-}\right)$approach a common value with an increase in polymer concentration. The polymer chains act on ion pairs to effect dissociation and the dissociated ions in the solvent are further solvated by the polymer chains which results in a change in carrier concentration $(n)$ and mobility $(\mu)$. Thus the addition of polymer has been found to affect the carrier concentration value.

In PEO based polymer gel electrolytes, the addition of PEO to the $1 \mathrm{M}$ solution of $\mathrm{LiCF}_{3} \mathrm{SO}_{3}$ in $\mathrm{EC} / \mathrm{PC}$ has been reported (Kim et al 2000) to result in an increase in conductivity at low polymer concentrations which has been explained to be due to a steady build up of free ions with an increase in PEO content. However, at higher PEO concentrations conductivity of gel electrolytes decreases due to an increase in local viscosity. The ion solvating ability of the polymer has been reported to be strongly correlated with the donor number of the polymer functional group and the ionic conductivity and cation transference number in gel electrolytes can be controlled by the donor number of the polymer component/solvent.

However, in the case of PEO based gel electrolytes with salicylic acid it has recently been found (Sekhon et al 2003) that the change in conductivity with polymer addition also depends upon the donor numbers of the solvent used. Solvent with high and low donor number show different conductivity behaviour in polymer gel electrolytes. On the basis of different experimental studies, it has been observed that increasing polymer concentration results in an increase in the mechanical stability of polymer gel electrolytes. It also results in a decrease in the ionic conductivity as it is governed by the mobility of the solvents. The existence of any interaction between polymer and liquid electrolyte does not modify the conductivity by a large amount. Gel electrolytes containing some other metal salts also show similar conductivity behaviour with the addition of polymer (Upadhyaya et al 2001).

Proton conducting polymer gel electrolytes is another promising category of gels with potential applications in fuel cells, electrochromic devices, supercapacitors, batteries etc. The high cost of Nafion membrane used in fuel cells has renewed interest in the search for an alternative proton conducting membranes with high value of conductivity suitable for fuel cell applications. Initial work on these materials was mainly with strong acids like $\mathrm{H}_{2} \mathrm{SO}_{4}, \mathrm{HCl}$ (Lassegeus et al 1989; Vaiars et al 1997). Due to high value of dissociation constant, these acids are fully dissociated in the electrolyte and hence provide large number of $\mathrm{H}^{+}$ions for conduction. However, the strong acids are likely to degrade the polymer used and 
as a result may not be suitable for practical applications.

Carboxylic acids which also provide $\mathrm{H}^{+}$ions upon dissociation and are relatively weak acids with varying values of dissociation constant (less than one in aqueous solution) may prove to be a better alternative. Keeping this in view, a program to develop non aqueous proton conducting polymer gel electrolytes containing different carboxylic acids was undertaken in our research group. Under this project, the following carboxylic acids have been chosen for study:

(A) Aromatic carboxylic acids: (i) benzoic acid, (ii) ortho-, meta- and para-hydroxybenzoic acids, (iii) ortho-, metaand para-nitrobenzoic acids, and (iv) ortho-, meta- and para-chlorobenzoic acids.

(B) Aliphatic dicarboxylic acids: $\mathrm{COOH}-\left(\mathrm{CH}_{2}\right)_{n}-\mathrm{COOH}$ : (i) oxalic acid $(n=0)$, (ii) malonic acid $(n=1)$, and (iii) succinic acid $(n=2)$.

The dissociation constant and other properties of these carboxylic acids are given in table 1 . Solvents based upon ethylene carbonate (EC), propylene carbonate (PC), dimethylacetamide (DMA) and dimethylformamide (DMF) with high dielectric constant and low viscosity as given in table 2 were used in the preparation of gel electrolytes. Gel electrolytes were prepared by using different polymers viz. polymethylmethacrylate (PMMA), poly-vinylidenefluoride (PVdF), polyvinylidenefluoride-co-hexafluoropropylene (PVdF-HFP) and polyethyleneoxide (PEO).

The conductivity of liquid electrolytes prepared by dissolving different carboxylic acids was studied as a function of acid concentration and representative results are given in figure 4 for electrolytes containing different aromatic carboxylic acids (a) and dicarboxylic acids (b). The results of figure 4 can be explained as follows:

- The conductivity of solvent $\left(\sim 10^{-6} \mathrm{~S} / \mathrm{cm}\right)$ increases by two to three orders of magnitude to $10^{-4}-10^{-3} \mathrm{~S} / \mathrm{cm}$ with the addition of different carboxylic acids.

- At low concentrations of acid, conductivity increases linearly with an increase in acid concentration due to the availability of free ions provided by the acid. It generally reaches a maximum value at moderate acid concentrations and then shows a saturation or even a small decrease at high acid concentrations which is due to the formation of ion aggregates which do not contribute to conductivity. However, the acid concentration at which the maximum conductivity or saturation is reached has been found to depend upon the nature of the acid used and its dissociation constant.

- The conductivity of different substituted (chloro $\left(\mathrm{Cl}^{-}\right)$, nitro $\left(\mathrm{NO}_{2}^{-}\right)$, hydroxy $\left(\mathrm{OH}^{-}\right)$and benzoic acid (BA)) carboxylic acids has been found to depend upon the nature of the substituted group and varies as:

$$
\sigma\left(\mathrm{Cl}^{-}\right)>\sigma\left(\mathrm{NO}_{2}\right)>\sigma\left(\mathrm{OH}^{-}\right)>\sigma(\mathrm{BA}) \text {. }
$$

This trend is in the order of the electron withdrawing power of the substituted group.
- The conductivity of electrolytes with different (ortho-, meta- and para-) hydroxy-, nitro- and chloro-benzoic acids varies as:

$$
\sigma\left(o^{-}\right)>\sigma(m-)>\sigma(p-),
$$

and this variation follows the dissociation constant values of the acid, which also varies as:

$$
K(o-)>K(m-)>K(p-),
$$

and is known as 'ortho effect'.

Table 1. Some physical properties of different $(o-, m$ - and $p$-) hydroxy, chloro and nitro substituted benzoic acids and simple aliphatic dicarboxylic acids.

\begin{tabular}{lcc}
\hline Acid & $\begin{array}{c}\text { MP } \\
\left({ }^{\circ} \mathrm{C}\right)\end{array}$ & $\begin{array}{c}\text { Dissociation constant } \\
\left(K_{\mathrm{a}}\right)\end{array}$ \\
\hline Benzoic acid & 122 & $6.5 \times 10^{-5}$ \\
$o$-Hydroxybenzoic acid & 158 & $105 \times 10^{-5}$ \\
$m$-Hydroxybenzoic acid & 202 & $8.3 \times 10^{-5}$ \\
$p$-Hydroxybenzoic acid & 214 & $2.6 \times 10^{-5}$ \\
$o$-Chlorobenzoic acid & 141 & $120 \times 10^{-5}$ \\
$m$-Chlorobenzoic acid & 154 & $15.1 \times 10^{-5}$ \\
$p$-Chlorobenzoic acid & 242 & $10.3 \times 10^{-5}$ \\
$o$-Nitrobenzoic acid & 147 & $670 \times 10^{-5}$ \\
$m$-Nitrobenzoic acid & 141 & $32 \times 10^{-5}$ \\
$m$-Nitrobenzoic acid & 242 & $36 \times 10^{-5}$ \\
Oxalic acid & 189 & $5400 \times 10^{-5}\left(K_{1}\right)$ \\
& & $5.2 \times 10^{-5}\left(K_{2}\right)$ \\
Malonic acid & 136 & $140 \times 10^{-5}\left(K_{1}\right)$ \\
& & $0.20 \times 10^{-5}\left(K_{2}\right)$ \\
Succinic acid & 185 & $6.4 \times 10^{-5}\left(K_{1}\right)$ \\
& & $0.23 \times 10^{-5}\left(K_{2}\right)$ \\
\hline
\end{tabular}

Table 2. Some important physical properties of the solvents.

\begin{tabular}{lcccc}
\hline Solvent & $\begin{array}{c}\text { MP } \\
\left({ }^{\circ} \mathrm{C}\right)\end{array}$ & $\begin{array}{c}\mathrm{BP} \\
\left({ }^{\circ} \mathrm{C}\right)\end{array}$ & $\begin{array}{c}\text { Viscosity } \\
(\eta)\end{array}$ & $\begin{array}{c}\text { Dielectric } \\
\text { constant } \\
(\varepsilon)\end{array}$ \\
\hline $\begin{array}{l}\text { Ethylene } \\
\text { carbonate } \\
\text { (EC) }\end{array}$ & 38 & 244 & 1.90 & 89 \\
$\begin{array}{l}\text { Propylene } \\
\text { carbonate } \\
\text { (PC) }\end{array}$ & -55 & 240 & 2.53 & 64.6 \\
$\begin{array}{l}\text { Dimethyl- } \\
\text { acetamide } \\
\text { (DMA) }\end{array}$ & -20 & 165 & 1.93 & 37.8 \\
$\begin{array}{l}\text { Dimethyl- } \\
\text { formamide } \\
\text { (DMF) }\end{array}$ & -61 & 153 & 0.80 & 36.7 \\
$\begin{array}{l}\text { Dimethyl- } \\
\text { sulphoxide } \\
\text { (DMSO) }\end{array}$ & 18.4 & 189 & 1.1 & 45 \\
\hline
\end{tabular}


- The conductivity of electrolytes containing aliphatic dicarboxylic acids varies as:

$$
\sigma(\mathrm{OA})>\sigma(\mathrm{MA})>\sigma(\mathrm{SA}),
$$

which also follows the first dissociation constant values of these dicarboxylic acids

$$
K_{1}(\mathrm{OA})>K_{1}(\mathrm{MA})>K_{1}(\mathrm{SA}),
$$

and is known as 'inductive effect'.

- Some undissociated acid shall also be present in all the electrolytes as the dissociation constant of these weak carboxylic acids is less than one. The percentage of undissociated acid shall however depend upon the dissociation constant of the acid and nature of the solvent used.

Gel electrolytes were prepared by adding different polymers (PMMA, PVdF, PVdF-HFP, PEO) to the solutions of different carboxylic acids in the ternary solvent mixture and containing different concentrations (in mola-
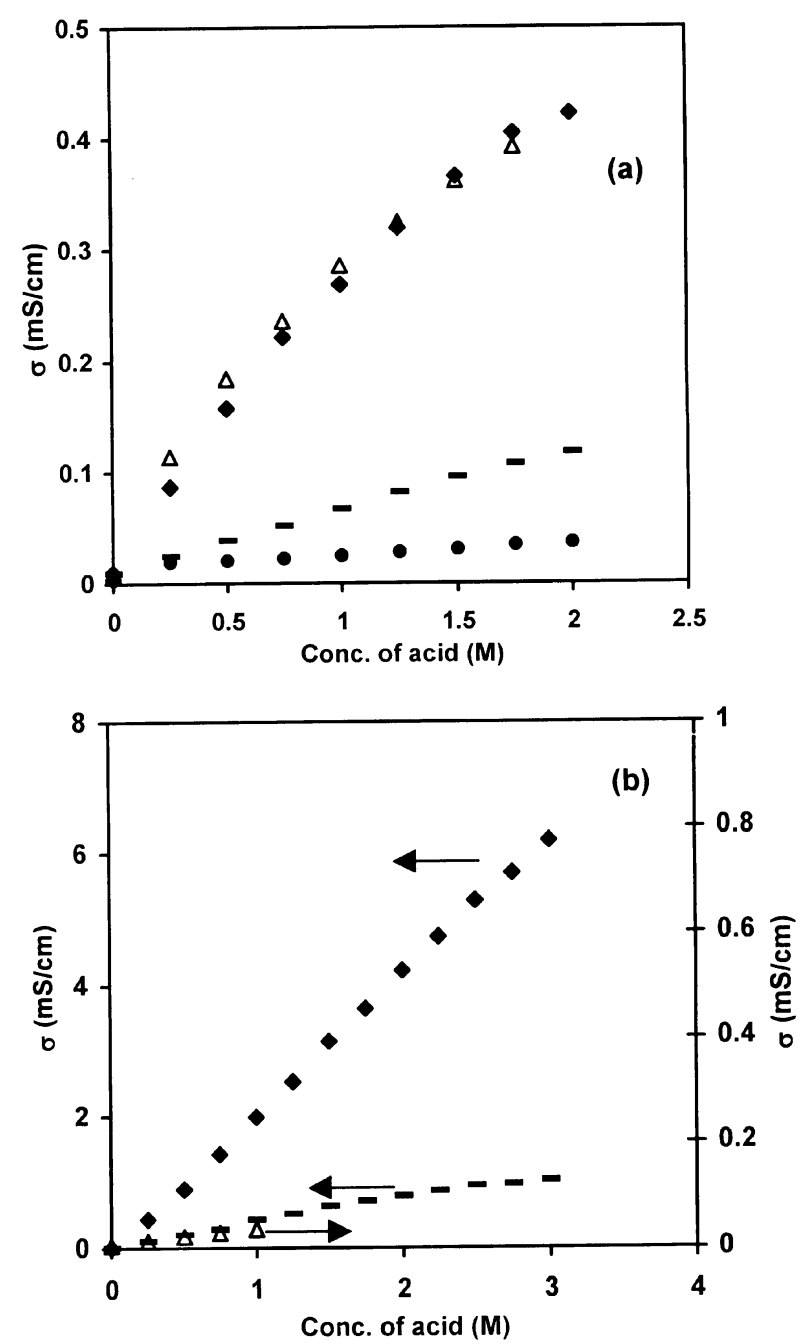

Figure 4. Variation of conductivity with acid concentration for liquid electrolytes containing (a) benzoic acid ( $\bullet$ ), chloro benzoic acid (-), hydroxy benzoic acid $(\bullet)$ and nitro benzoic acid $(\Delta)$ and (b) containing oxalic acid $(\diamond)$, malonic acid (-) and succinic acid $(\Delta)$ in EC : PC : DMA. rity value) of the acids. The variation of conductivity of gel electrolytes as a function of PMMA, PVdF, PVdFHFP and PEO content are given in figures 5-8, respectively. The conductivity of liquid electrolytes has been observed to increase with the addition of polymer i.e.

$$
\sigma(\text { gel })>\sigma \text { (liquid) }
$$

Such behaviour has been observed with electrolytes containing different carboxylic acids as well as with different polymers used in the present study. These results are contrary to the results of lithium ion conducting polymer gel electrolytes in which the addition of polymer results in a decrease in conductivity as already shown in figures 1-3.

The conductivity $(\sigma)$ of an electrolyte given by $\sigma=$ $n q \mu$ depends upon the carrier concentration $(n)$ and mobility $(\mu)$. The mobility is inversely related to the viscosity ( $\eta$ ) of the electrolyte as $\mu=q / 6 \pi r \eta$. The addition of polymer to the liquid electrolyte results in an increase in the viscosity, which decreases mobility, and hence conductivity also decreases. The decrease in conductivity with polymer addition in the case of lithium ion conducting polymer gel electrolytes is generally explained on the basis of this reasoning. However, the conductivity can show an increase if with the addition of polymer, carrier concentration $(n)$ also increases and secondly the increase in ' $n$ ' is more than the decrease in $\mu$ observed with polymer addition. The increase in ' $n$ ' with polymer addition can be explained as follows:

The carboxylic acids used in the present study are weak acids with dissociation constant (in aqueous solution) less than one as given in table 1. Thus these acids

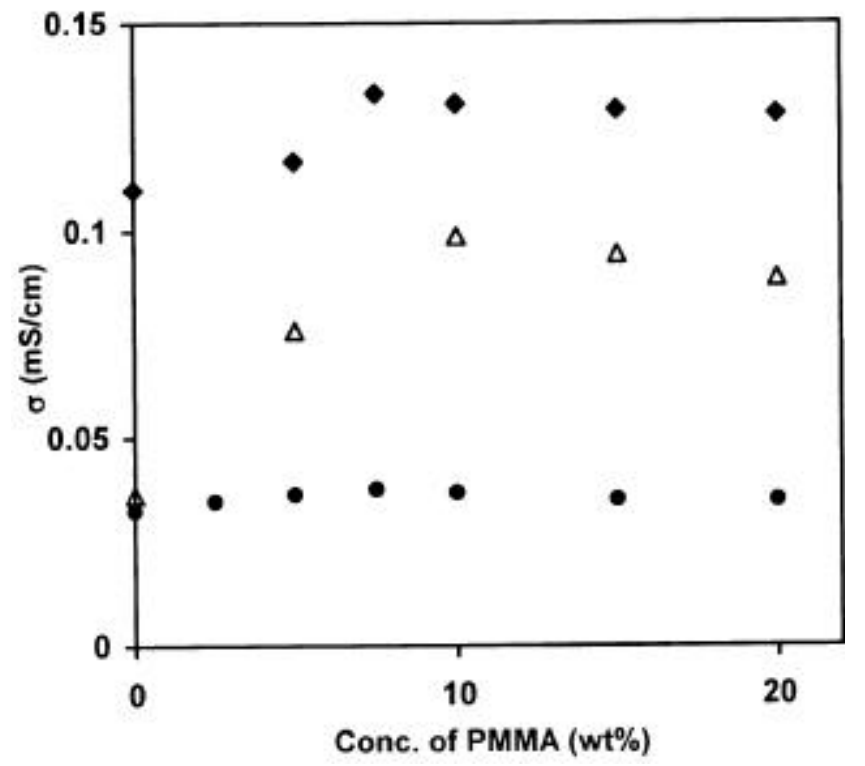

Figure 5. Variation of conductivity with PMMA concentration for gel electrolytes containing $1 \mathrm{M}$ succinic acid (•), hydroxy benzoic acid $(\Delta)$ and nitro benzoic acid $(\diamond)$ in EC : PC : DMF. 
shall not be fully dissociated in the electrolyte and some undissociated acid shall also be present. The fraction/ quantity of undissociated acid shall further depend upon the dissociation constant of the acid used and the nature of the solvent. If the addition of polymer results in the dissociation of undissociated acid, then ' $n$ ' shall increase and as a result increase in conductivity will be observed. The polymer can also help in the dissociation of ion

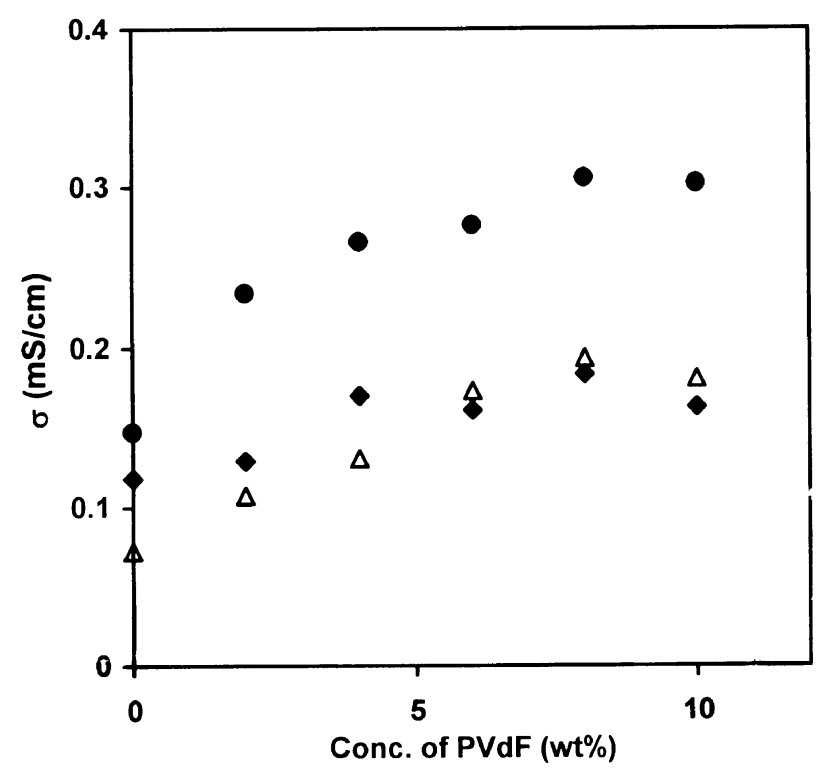

Figure 6. Variation of conductivity with $\mathrm{PVdF}$ concentration for gel electrolytes containing $1 \mathrm{M}$ succinic acid $(\diamond)$, chloro benzoic acid $(\Delta)$ and $0.5 \mathrm{M}$ hydroxy benzoic acid $(\bullet)$ in EC : PC : DMA.

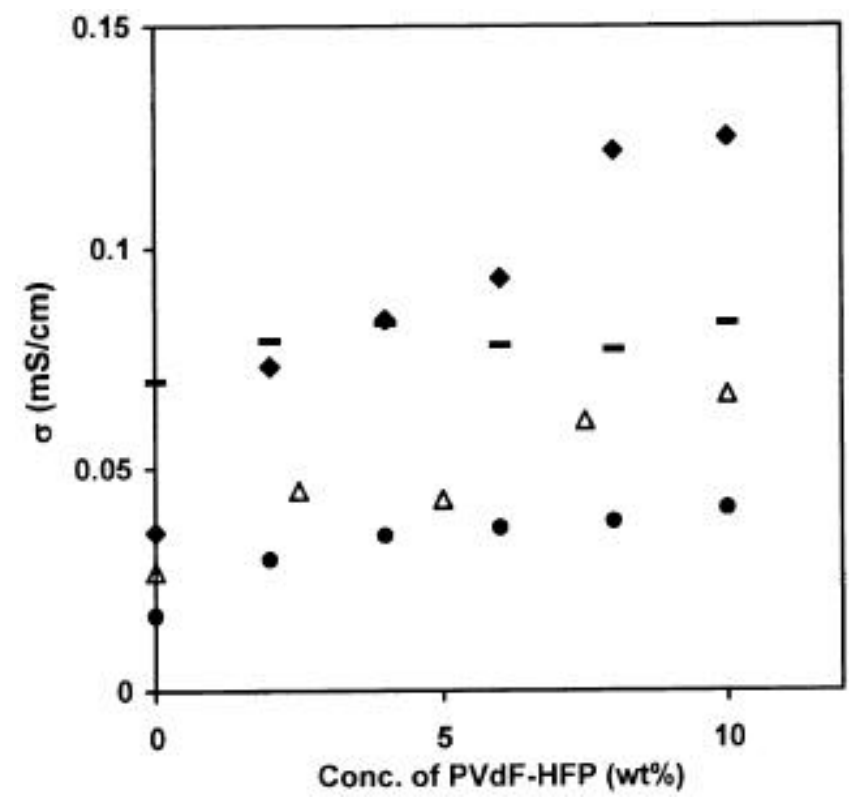

Figure 7. Variation of conductivity with PVdF-HFP concentration for gel electrolytes containing $1 \mathrm{M}$ succinic acid $(\bullet)$, benzoic acid $(\bullet)$, hydroxy benzoic acid $(\Delta)$ and chloro benzoic acid (-) in EC : PC : DMA. aggregates present in electrolytes at higher acid concentrations as mentioned in the variation of conductivity with acid concentration given in figure 4 . However, this net increase in conductivity observed is despite the increase in viscosity with polymer addition which lowers mobility and hence conductivity. Secondly the addition of polymer also results in a decrease in molarity of acid in the gel electrolytes as no acid is added and low acid concentration should also decrease conductivity. The increase in conductivity of electrolytes containing different $(o-, m$ - and $p$-) hydroxy benzoic acids and aliphatic dicarboxylic acids with the addition of PMMA has earlier been explained by 'Breathing polymeric chain model' proposed by us (Chandra et al 2000). According to this model polymer gel electrolytes generally consist of free ions, ion aggregates and polymer chains dispersed in the gel matrix. The breathing of the polymer by folding/unfolding up of its chains results in density/pressure fluctuations at the microscopic level which assist the motion of ions alongwith the dissociation of ion aggregates/ undissociated acid which results in an increase in conductivity. Similar results have been obtained with proton conducting polymer gel electrolytes containing other carboxylic acids, dicarboxylic acids and different polymers like PVdF, PVdF-HFP, PEO and PMMA (Ericson et al 2000; Wieczorek et al 2001; Sekhon et al 2002; Singh and Sekhon 2002).

These results are in agreement with similar studies on PMMA based proton conducting polymer gel electrolytes containing salicylic acid in which gel electrolytes have been reported to have higher conductivity than the corresponding liquid electrolyte (Grillone et al 1999). This has been attributed to a specific interaction between the poly-

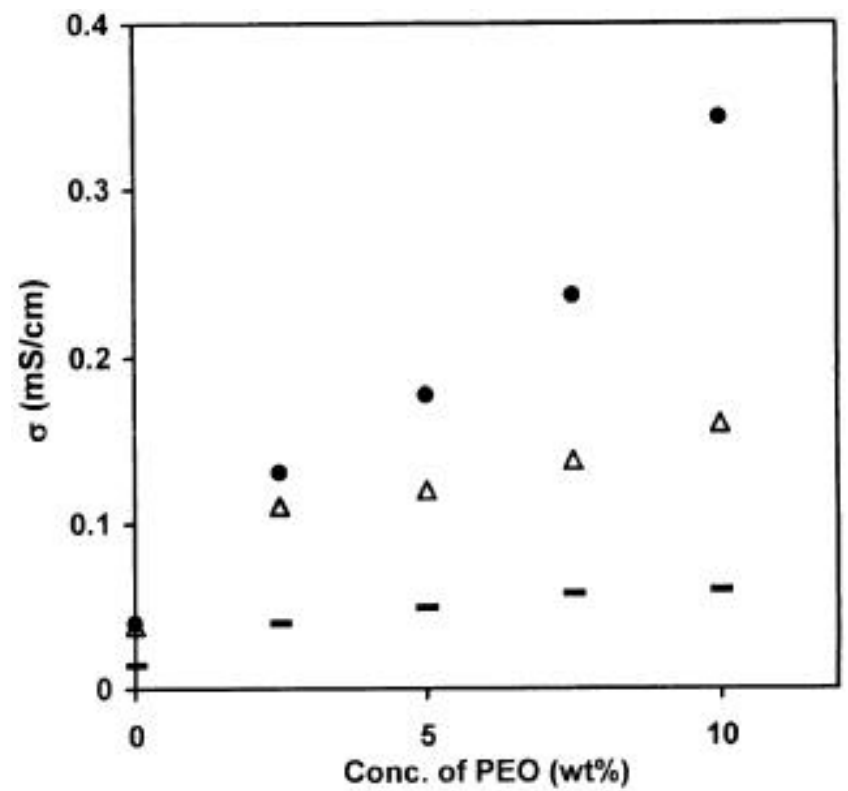

Figure 8. Variation of room temperature conductivity with PEO concentration for gel electrolytes containing $1 \mathrm{M}$ hydroxy benzoic acid in DMF $(\bullet), \mathrm{EC}: \mathrm{PC}(-)$ and EC : PC : DMF $(\Delta)$. 
mer and the non-polar segment of the acid molecule and as a result more charge carriers are expected to be active in the gel than in the solution electrolyte. The presence of undissociated acid in gel electrolytes containing benzoic acid and salicylic acid has also been studied by Raman spectroscopy (Ericson et al 2000) and the fraction of dissociated acid in these gels has been reported to be in the $0 \cdot 1-0.6$ range which proves the presence of undissociated acids in these electrolytes. Similar results have also been reported for $\mathrm{H}_{3} \mathrm{PO}_{4}$ containing gel electrolytes having composition GMA-DMF- $\mathrm{H}_{3} \mathrm{PO}_{4}$ (Wieczorek et al 2001). The gel electrolytes containing 23 and 7.4 mass $\% \mathrm{H}_{3} \mathrm{PO}_{4}$ have been found to have higher conductivity than the corresponding liquid electrolytes. It has been reported that the use of glycidyl methacrylate (GMA) (Wieczorek et al 2001) as a part of the polymer matrix enhances the ionic conductivity due to the reaction between GMA and $\mathrm{H}_{3} \mathrm{PO}_{4}$.

Why such an increase in conductivity has not been observed in lithium ion conducting polymer gel electrolytes? The answer to this question is that in the case of lithium ion conducting polymer gel electrolytes, lithium salts used with bigger anions have very low dissociation energy and are nearly fully dissociated in the electrolytes. The study of variation of conductivity with lithium salt concentration always shows the presence of ion aggregates at higher salt concentration values. The presence of large salt concentration also leads to an increase in viscosity and as a result the viscosity is the dominant factor in those electrolytes. As the salts are fully dissociated, so a large number of free ions shall be present and the dissociation of ion aggregates by polymer addition

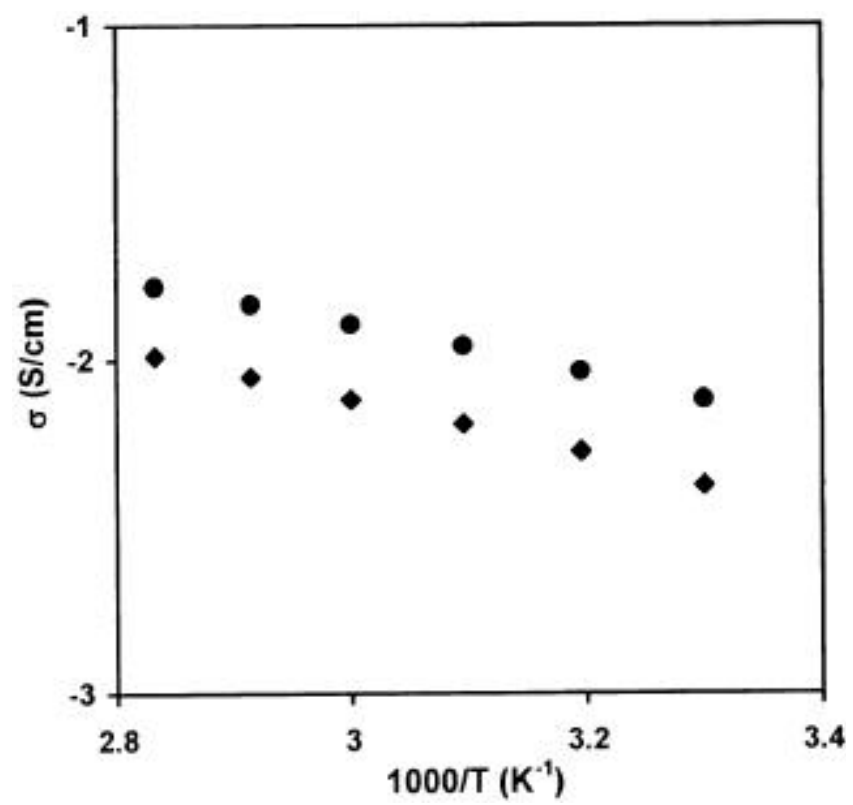

Figure 9. Variation of conductivity with temperature for liquid and gel electrolytes containing $1 \mathrm{M} \mathrm{LiClO}_{4}$ with $0(\bullet)$ and 20 $(\diamond)$ wt.\% PMMA. (if any) shall be negligible in comparison with total ion concentration and as a result net increase in conductivity is not observed.

However, in the case of proton conducting polymer gel electrolytes containing weak acids, although the addition of polymer:

- increases viscosity which lowers mobility and hence conductivity;

- lowers net concentration of acid in the electrolyte and hence conductivity shall be lower;

- increases acid dissociation which increases ' $n$ ' and hence conductivity shall increase.

The net increase in conductivity observed with polymer addition as shown in figures 5-8 for different gel systems suggests that the increase in carrier concentration is dominant factor in these gel electrolytes. This is very advantageous for device applications. We have liquid electrolyte with certain value of conductivity. The polymer is added to increase its mechanical stability and it also results in an increase in conductivity. Thus in comparison to liquid electrolytes, we have polymer gel electrolytes with higher conductivity and higher mechanical stability. Thus polymer used in proton conducting polymer gel electrolytes does not act as a stiffener only but also helps in acid dissociation, which increases carrier concentration and as a result conductivity increases.

The variation of conductivity has also been studied as a function of temperature and the results are given in figure 9 for lithium ion conducting and in figure 10 for proton conducting liquid and gel electrolytes. It has been observed that the conductivity of lithium ion conducting gel electrolytes is lower than the conductivity of liquid

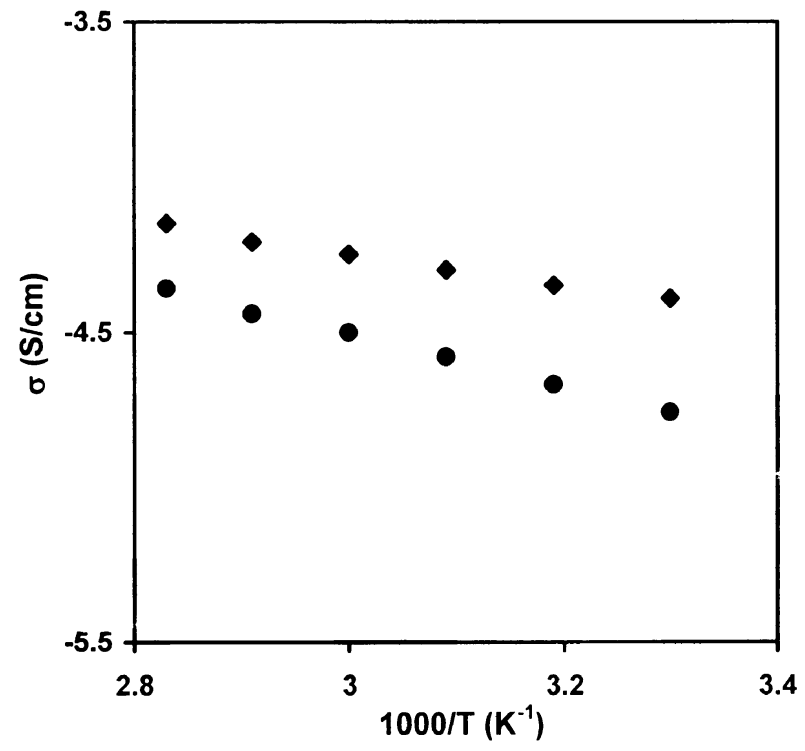

Figure 10. Variation of conductivity with temperature for liquid and gel electrolytes containing $1 \mathrm{M}$ benzoic acid with 0 $(\bullet)$ and $10(\bullet)$ wt.\% PVdF-HFP. 
electrolytes at different temperatures whereas in the case of proton conducting polymer gel electrolytes the conductivity of gel electrolytes is higher than the conductivity of liquid electrolytes at all temperatures studied and secondly the variation of conductivity with temperature for gel electrolytes is similar to that for liquid electrolytes which shows the liquid like behaviour of these gel electrolytes.

\section{Conclusions}

The role of polymer in gel electrolytes has been found to depend upon the nature of salt used. In the case of lithium ion conducting polymer gel electrolytes containing various lithium salts-which are nearly fully dissociated-the addition of polymer results in an increase in viscosity which lowers mobility and conductivity decreases. Whereas in the case of proton conducting polymer gel electrolytes containing weak carboxylic acids, the acids are not fully dissociated in the electrolytes. The addition of polymer in addition to an increase in viscosity also helps in increasing carrier concentration by dissociating undissociated acid/ion aggregates present in these gel electrolytes and gel electrolytes with net conductivity higher than the corresponding liquid electrolytes has been observed. The variation of conductivity of gel electrolytes with temperature shows liquid like behaviour.

\section{References}

Abraham K M and Alamgir M 1994 Solid State Ionics 70-71 311

Agnihotry S A, Nidhi, Pradeep and Sekhon S S 2000 Solid State Ionics 136-137 573

Arora N and Sekhon S S 2000 in Solid state ionics: materials and devices (eds) B V R Chowdari and W Wang (Singapore: World Scientific) p. 443

Bohnke O, Frand G, Resrazi M, Rousselet C and Truche C 1993 Solid State Ionics 6697

Cazanelli E, Mariotto G, Appectecchi G B, Croce F and Scrosati B 1995 Electrochim. Acta 402379

Chandra S, Sekhon S S and Arora N 2000 Ionics 6112
Colomban P (ed.) 1992 Proton conductors: solids, membranes and gels-materials and devices (Cambridge: Cambridge University Press)

Ericson H, Svanberg C, Brodin A, Grillone A M, Panero S and Scrosati B 2000 Electrochim. Acta 451409

Feuillade G and Perche P 1975 J. Appl. Electrochem. 563

Grillone A M, Panero S, Retamal B A and Scrosati B 1999 J. Electrochem. Soc. 14627

Kim C S and Oh S M 2000 Electrochim. Acta 452101

Koksbang R, Oslen I I and Shackle D 1994 Solid State Ionics 69320

Lassegeus J C, Desbat B, Trinquet O, Cruege F and Poinsignon C 1989 Solid State Ionics 3517

Osada Y and Kajiwara K (eds) 2001 Gels handbook (San Diego: Academic Press) Vol. 1

Ostrovskii D, Torell L M, Appetecchi G B and Scrosati B 1998 Solid State Ionics 10619

Qureshi M Y, Berstan D, Cameron G G, Ingram M D and Rousselot C 1998 Polym. Int. 4716

Saito Y, Kataoka H, Capiglia C and Yamamoto H 2000 J. Phys. Chem. B104 2189

Scrosati B 2000 Electrochim. Acta 452461

Sekhon S S and Singh H P 2002 Solid State Ionics 152-153 167

Sekhon S S, Pradeep and Agnihotry S A 1998 in Solid state ionics: science and technology (eds) B V R Chowdari et al (Singapore: World Scientific) p. 217

Sekhon S S, Deepa and Agnihotry S A 2000 Solid State Ionics 136-137 1189

Sekhon S S, Arora N, Singh B and Chandra S 2002 J. Mater. Sci. 372159

Sekhon S S, Arora N and Chandra S 2003 Eur. Polym. J. 39915

Singh H P and Sekhon S S 2002 Eur. Polym. J. 3993

Svanberg C, Adebahr J, Bergman R, Borjesson L, Scrosati B and Jacobsson P 2000 Solid State Ionics 136-137 1147

Upadhyaya H M, Yadav R K, Thakur A K and Hashmi S A 2001 in Ion conducting materials: theory and applications (eds) A R Kulkarni et al (New Delhi: Narosa) p. 111

Vaiars G, Kleperis J, Azens A, Granqvist C G and Lusis A 1997 Solid State Ionics 97365

Wang Z, Huang B, Xue R, Huang X and Chen L 1999 Solid State Ionics 121141

Weber A 1991 J. Electrochem. Soc. 1382586

Wieczorek W, Zukowska G, Borkowska R, Chung S H and Greenbaum S 2001 Electrochim. Acta 461427 